\title{
PENINGKATAN KINERJA HIJAU MELALUI RETROFITTING STUDI KASUS : PEKERJAAN PENGUBAHSUAIAN BANGUNAN PIP2B DIY
}

\author{
Ani Hastuti Arthasari*)
}

*) Corresponding author email : arthasari@amikom.ac.id

Program Studi Arsitektur, Fakultas Sains dan Teknologi, Universitas Amikom Yogyakarta

\begin{tabular}{l} 
Article info \\
MODUL vol 20 no 1, issues period 2020 \\
\hline Doi $\quad: 10.14710 /$ mdl.20.1.2020.57-65 \\
Received : 16 Maret 2020 \\
Revised : 2 Mei 2020 \\
Accepted : 7 Mei 2020
\end{tabular}

\section{Abstrak}

Permasalahan yang terjadi di hampir semua negara adalah kemiskinan, kesenjangan sosial dan lingkungan. Di sisi lain, pembangunan terus dilakukan untuk mendukung semua kegiatan kehidupan manusia. Arsitektur sebagai ilmu perancangan dapat berperan dalam mengarahkan pembangunan agar dalam proses perancangan dan pelaksanaannya dapat menciptakan harmonisasi ekonomi, sosial dan lingkungan. Pembangunan berwawasan lingkungan juga didukung oleh pemerintah pada level kebijakan berupa Peraturan Menteri Pekerjaan Umum dan Perumahan Rakyat Republik Indonesia Nomor 02/PRT/M/2015 Tentang Bangunan Gedung Hijau. Tujuan penelitian ini adalah untuk mengetahui penerapan konsep bangunan hijau pada kegiatan pengubahsuaian (retrofitting) Bangunan Kantor Pusat Informasi Pengembangan Pemukiman dan Bangunan yang dinilai dengan tolok ukur dan kriteria Permen PU No 2 Tahun 2015. Metode penelitian yang digunakan adalah kualitatif induktif dengan pendekatan deskriptif. Melalui penelitian ini diharapkan dapat memberi kontribusi pada ilmu pengetahuan arsitektur terutama mengenai konsep dan pemeringkatan bangunan hijau. Hasil yang didapatkan adalah gambaran upaya yang bisa dilakukan untuk menaikkan nilai peringkat bangunan pra hijau menjadi bangunan hijau..

Kata kunci: bangunan hijau; green retrofitting; studi kasus

Ani Hastuti Arthasari

\section{Pendahuluan}

Permasalahan yang terjadi di hampir semua negara adalah kemiskinan, kesenjangan sosial dan lingkungan. Sehingga mulai tahun 2015 dicapai kesepakatan global tentang Tujuan Pembangunan Berkelanjutan atau sering disebut sebagai Sustainable Development Goals (SDG's), yang berisi 17 tujuan dan 169 target yang diharapkan akan dapat dicapai pada tahun 2030. Indonesia sebagai bagian dari dunia juga turut mendukung SDG's melalui berbagai bidang. Terdapat tiga elemen penting yang perlu diharmonisasikan agar SDG's dapat tercapai, yaitu pertumbuhan ekonomi (economic growth), keterlibatan sosial (social inclusion), dan perlindungan lingkungan (environmental protection).

Di sisi lain, pembangunan terus dilakukan untuk mendukung semua kegiatan kehidupan manusia. Arsitektur sebagai ilmu perancangan dapat berperan dalam mengarahkan pembangunan agar dalam proses perancangan dan pelaksanaannya dapat menciptakan harmonisasi ekonomi, sosial dan lingkungan. Perkembangan dalam dunia arsitektur belakangan ini adalah munculnya 'arsitektur hijau' yang menjadi gerakan dan idealisme dalam berarsitektur.

Pembangunan berwawasan lingkungan juga didukung oleh pemerintah pada level kebijakan berupa Peraturan Menteri Pekerjaan Umum dan Perumahan Rakyat Republik Indonesia Nomor 02/PRT/M/2015 Tentang Bangunan Gedung Hijau. Melalui peraturan ini, pemerintah ingin mendorong terwujudnya penyelenggaraan bangunan gedung berkelanjutan yang ditandai dengan efisiensi penggunaan sumber daya dan adanya kontribusi terhadap pengurangan emisi gas rumah kaca (emisi GRK).

Munculnya peraturan tersebut menambah ketersedian alat ukur yang dapat digunakan untuk menilai kinerja bangunan hijau, selain Greenship yang dikeluarkan oleh Green Building Council (GBCI) yang sudah lebih dulu diperkenalkan di Indonesia. 
Upaya berkelanjutan melalui penyelenggaraan bangunan hijau akan efektif jika semakin banyak bangunan yang memenuhi kriteria bangunan hijau. Sehingga untuk pembangunan gedung baru didorong kesesuaiannya dengan kriteria bangunan hijau.

Padahal jumlah bangunan baru yang dibangun sangat sedikit jumlahnya dibandingkan bangunan eksisting (Rahmawati, dkk, 2018). Disisi lain kegiatan meruntuhkan bangunan eksisting untuk mengganti dengan bangunan hijau bukanlah pilihan yang baik (Husin, 2017). Maka pengubahsuaian (green retrofitting) menjadi pilihan yang paling tepat untuk menjadikan bangunan lebih berkelanjutan.

Faktor yang paling kuat berpengaruh dalam intensitas green retrofitting adalah faktor kebijakan. (He, 2019). Maka contoh terbaik bisa dilakukan melalui green retrofitting pada bangunan milik penyusun kebijakan itu sendiri, dalam hal ini Departemen PUPR.

Penelitian ini dilakukan di Kantor Pusat Informasi Pengembangan Pemukiman dan Bangunan (PIP2B) di bawah Departemen PUPR yang terletak di Jalan Kenari Timoho Yogyakarta, untuk mengetahui sejauh mana bangunan tersebut dapat memenuhi persyaratan sebagai bangunan hijau dan bagaimana upaya yang dilakukan dalam memenuhi kriteria sebagai bangunan hijau.

\section{Studi Pustaka \\ State of The Art}

Penelitian-penelitian sebelumnya yang berkaitan dengan penilaian peringkat kinerja bangunan yang dilakukan di Indonesia maupun di luar Indonesia, menggunakan alat ukur yang bersuMber dari Green Building Council.

Untuk area Indonesia, penelitian denngan parameter Greensip GBCI banyak dilakukan antara lain pada obyek bangunan gedung rumah sakit (Fernando, dkk, 2015), kantor (Fikriyah dan Putranto, 2017), bangunan pendidikan (Rahmawati, dkk., 2018).

Fernando dkk (2015) dan Fikriyah dkk (2017) lebih berfokus pada penilaian dan pencapaian kinerja bangunan dan memberikan saran tentang cara-cara untuk meningkatkan kinerja bangunan

Rahmawati dkk (2018) menambahkan pembahasan retrofitiing dengan mengkaitkan antara hasil pencapaian kriteria hijau Greenship GBCI dengan perhitungan penghematan biaya, yaitu dengan cara membandingkan biaya operasional dan pemeliharaan sebelum dan sesudah kegiatan retrofit.

Rujukan penelitian tentang bangunan hijau di luar Indonesia juga menggunakan kriteria-kriteria dari Green Building Council yang ada di negara masingmasing, misal pada penelitian Al-Khodmany (2014) menggunakan rujukan LEED dari U.S. Green Building Council.
Al-Khodmany (2014) mereview upaya green retrofitting pada kasus bangunan tinggi. Sisi pendorong kegiatan retrofit terdiri dari aspek ekonomi, lingkungan, pemerintah, dan trend baru bangunan hijau. Hal yang umum dilakukan dalam kegiatan retrofit adalah pada aspek (1) pencahayaan, (2) heating, ventilation dan air conditioning, (3) water systems, (4) sistem otomasi bangunan, (5) insulasi, (6) on-site energy generations, dan (7) innovasi. Pada studi kasus bangunan tinggi, retrofit dinilai lebih berkelanjutan daripada meruntuhkan dan membangunnya kembali menjadi bangunan hijau.

Pembahasan tentang oleh $\mathrm{He}, \mathrm{Q}$, dkk (2019) juga membahas tentang faktor-faktor yang mempengaruhi intensitas pengguna dalam melakukan green retrofitting pada bangunan rumah tinggal. Disini didapatkan bahawa faktor kebijakan merupakan faktur yang memiliki pengaruh besar terhadap intensitas residen dalam melakukan green retrofitting.

Berbeda dengan penelitian-penelitian sebelumnya, penelitian ini menggunakan instrumen (rating tools) bukan dari Green Building Council, akan tetapi menggunakan daftar simak yang disediakan oleh Pemerintah yang ada di dalam Surat Edaran Dirjen Cipta Karya 86/SE/DC/2016 tentang Penyelenggaraan Bangunan Gedung Hijau. Dengan demikian dapat memberi gambaran yang berbeda tentang poin-poin pemeringkatan dan dapat digunakan sebagai pembanding dengan rating tools yang lain. Penelitian ini sekaligus juga membahas tentang upaya green retrofitting yang dilakukan pada bangunan.

\section{Definisi Bangunan Hijau}

Bangunan Gedung Hijau adalah bangunan gedung yang memenuhi persyaratan bangunan gedung dan memiliki kinerja terukur secara signifikan dalam penghematan energi, air, dan sumber daya lainnya melalui penerapan prinsip bangunan gedung hijau sesuai dengan fungsi dan klasifikasi dalam setiap tahapan penyelenggaraannya (Permen PUPR Nomor 2 Tahun 2015 Pasal 1).

Green Architecture ialah sebuah konsep arsitektur yang berusaha meminimalkan pengaruh buruk terhadap lingkungan alam maupun manusia dan menghasilkan tempat hidup yang lebih baik dan lebih sehat, yang dilakukan dengan cara memanfaatkan sumber energi dan sumber daya alam secara efisien dan optimal (Sudarwani, 2012).

Green building adalah konsep untuk 'bangunan berkelanjutan' dan mempunyai syarat tertentu, yaitu lokasi, sistim perencanaan dan perancangan, renovasi dan pengoperasian, yang menganut prinsip hemat enrgi serta harus berdampak positif bagi lingkungan, ekonomi dan sosial (Sudarwani, 2012). 


\section{Definisi Green Retrofitting (pengubahsuaian)}

Green Retrofitting merupakan usaha perbaikan bangunan eksisting dengan menambahkan perlengkapan hemat energi dan fitur hijau yang belum dipasang selama proses konstruksi sebelumnya (Husin, 2017)

\section{Alat Ukur (Tools) Kriteria Bangunan Hijau}

Pedoman bagi penyelenggara bangunan gedung dalam melakukan penyelenggaraan bangunan gedung hijau adalah berdasarkan Permen PUPR No. 2 Tahun 2015 tentang Bangunan Hijau.

Penyelenggaraan bangunan gedung menurut Undang-undang Nomor 28 Tahun 2002 tentang Bangunan Gedung, adalah kegiatan pembangunan yang meliputi proses perencanaan teknis dan pelaksanaan konstruksi, serta kegiatan pemanfaatan, pelestarian, dan pembongkaran. Setiap tahapan penyelenggaraan bangunan gedung dapat dinilai menggunakan daftar simak berbentuk form sebagai alat untuk melakukan penilaian kinerja bangunan gedung hijau. Daftar simak tersebut dijabarkan dalam Surat Edaran Dirjen Cipta Karya 86/SE/DC/2016 tentang Penyelenggaraan Bangunan Gedung Hijau.

Pada tahap perencanaan, daftar simak digunakan sebagai alat untuk menilai rencana teknis bangunan yang telah memenuhi persyaratan teknis untuk diterbitkan IMB. Pada tahap pelaksanaan konstruksi, daftar simak digunakan sebagai alat untuk menilai paska konstruksi terhadap pernerapan praktik hijau dalam pelaksanaan konstruksi dari sebuah perencanaan bangunan gedung hijau sebelum bangunan hijau di manfaatkan. Pada tahap pemanfaatan, daftar simak digunakan sebagai sebagai alat untuk menilai bangunan gedung hijau pada masa pemanfaatan.

\section{Form Penilaian Kinerja Bangunan Hijau Pada Tahap Perencanaan}

Penelitian ini menggunakan form penilaian kinerja tahap perencanaan dalam melakukan analisis pencapaian kinerja, sesuai dengan pentahapan yang dikerjakan pada kegiatan retrofitting, yaitu pada tahapan perencanaan.

Tabel 1 merupakan daftar simak yang memuat tentang hal-hal yang diukur pada Tahap Perencanaan Teknis yang meliputi persyaratan teknis atas (1) pengelolaan tapak, (2) efisiensi penggunaan energi, (3) efisiensi penggunaan air, (4) kualitas udara dalam ruang, (5) penggunaan material ramah lingkungan, (6) pengelolaan sampah, dan (7) pengelolaan air limbah. Masing-masing persyaratan tersebut memiliki poin untuk mengukur ketercapaian kinerja tahap perencanaan. Total poin maksimal yang bisa dicapai pada tahap perencanaan adalah 167.
Tabel 1. Daftar Simak Kinerja Bangunan Hijau

\begin{tabular}{|c|c|c|c|c|}
\hline NO & & PERSYARATAN & $\begin{array}{c}\text { Jumlah } \\
\text { Persyaratan }\end{array}$ & $\begin{array}{c}\text { Poin } \\
\text { Acuan }\end{array}$ \\
\hline \multirow[t]{10}{*}{ A } & \multicolumn{4}{|c|}{ Pengelolaan Tapak } \\
\hline & 1 & Orientasi Bangunan & 3 & 4 \\
\hline & 2 & $\begin{array}{l}\text { Pengolahan Tapak termasuk } \\
\text { Aksesibilitas/ Sirkulasi } \\
\text { Pengelolaan Lahan }\end{array}$ & 4 & 8 \\
\hline & 3 & $\begin{array}{l}\text { Terkontaminasi Limbah Bahan } \\
\text { Berbahaya dan Beracun (B3) }\end{array}$ & 1 & 3 \\
\hline & 4 & $\begin{array}{l}\text { Rencana Ruang Terbuka Hijau } \\
\text { (RTH) Privat }\end{array}$ & 5 & 5 \\
\hline & 5 & $\begin{array}{l}\text { Penyediaan Jalur Pejalan Kaki } \\
\text { (Pedestrian) }\end{array}$ & 4 & 7 \\
\hline & 6 & Pengelolaan Tapak Besmen & 1 & 2 \\
\hline & 7 & Penyediaan Lahan Parkir & 1 & 3 \\
\hline & 8 & $\begin{array}{l}\text { Sistem Pencahayaan Ruang } \\
\text { Luar atau Halaman }\end{array}$ & 1 & 3 \\
\hline & 9 & $\begin{array}{l}\text { Pembangunan Bangunan } \\
\text { Gedung di atas dan/ atau di } \\
\text { Bawah Tanah, Air dan/atau } \\
\text { Prasarana/ Sarana Umum }\end{array}$ & 3 & 6 \\
\hline \multirow[t]{7}{*}{ B } & \multicolumn{4}{|c|}{ Efisiensi Penggunaan Energi } \\
\hline & 1 & Selubung Bangunan & 3 & 12 \\
\hline & 2 & Sistem Ventilasi & 1 & 4 \\
\hline & 3 & Sistem Pengkondisian Udara & 2 & 7 \\
\hline & 4 & Sistem Pencahayaan & 5 & 12 \\
\hline & 5 & $\begin{array}{l}\text { Sistem Transportasi dalam } \\
\text { gedung }\end{array}$ & 2 & 2 \\
\hline & 6 & Sistem Kelistrikan & 1 & 3 \\
\hline \multirow[t]{4}{*}{$\mathrm{C}$} & \multicolumn{4}{|c|}{ Efisiensi Penggunaan Air } \\
\hline & 1 & Sumber Air & 5 & 12 \\
\hline & 2 & Pemakaian Air & 3 & 8 \\
\hline & 3 & $\begin{array}{l}\text { Penggunaan Peralatan Saniter } \\
\text { Hemat Air (Water Fixture) }\end{array}$ & 1 & 5 \\
\hline \multirow[t]{4}{*}{$\mathrm{D}$} & \multicolumn{4}{|c|}{ Kualitas Udara dalam Ruang } \\
\hline & 1 & Pelarangan Merokok & 2 & 5 \\
\hline & 2 & Pengendalian $\mathrm{CO}_{2}$ dan $\mathrm{CO}$ & 3 & 9 \\
\hline & 3 & $\begin{array}{l}\text { Pengendalian penggunaan } \\
\text { bahan pembeku (refrigerant) }\end{array}$ & 1 & 5 \\
\hline \multirow[t]{3}{*}{$\mathrm{E}$} & \multicolumn{4}{|c|}{ Material Ramah Lingkungan } \\
\hline & 1 & $\begin{array}{l}\text { Pengendalian Penggunaan } \\
\text { Material Berbahaya } \\
\text { Penggunaan Material }\end{array}$ & 4 & 7 \\
\hline & 2 & $\begin{array}{l}\text { Bersertifikat Ramah } \\
\text { Lingkungan (Eco Labelling) }\end{array}$ & 6 & 11 \\
\hline \multirow[t]{4}{*}{$\mathrm{F}$} & \multicolumn{4}{|c|}{ Pengelolaan Sampah } \\
\hline & 1 & $\begin{array}{l}\text { Penerapan Prinsip 3R (reduce, } \\
\text { reuse, recycle) }\end{array}$ & 1 & 3 \\
\hline & 2 & $\begin{array}{l}\text { Penerapan Sistem Penanganan } \\
\text { Sampah }\end{array}$ & 4 & 5 \\
\hline & 3 & $\begin{array}{l}\text { Penerapan Sistem Pencatatan } \\
\text { Timbulan Sampah }\end{array}$ & 2 & 2 \\
\hline \multirow[t]{4}{*}{ G } & \multicolumn{4}{|c|}{ Pengelolaan Air Limbah } \\
\hline & 1 & $\begin{array}{l}\text { Penyediaan Fasilitas } \\
\text { Pengelolaan Limbah Padat dan } \\
\text { Limbah Cair Sebelum Dibuang } \\
\text { ke Saluran Pembuangan Kota }\end{array}$ & 3 & 9 \\
\hline & 2 & $\begin{array}{l}\text { Daur ulang air yang berasal } \\
\text { dari limbah cair (grey water) }\end{array}$ & 2 & 5 \\
\hline & \multicolumn{3}{|c|}{ TOTAL POINT } & 167 \\
\hline
\end{tabular}

Sumber: Lampiran SE Dirjen Cipta Karya No. 86/SE/DC/2016 


\section{Pemeringkatan Kinerja Bangunan Hijau Pada Tahap Perencanaan}

Pemeringkatan digunakan untuk menunjukkan sejauh mana penerapan sebagai persyaratan bangunan gedung hijau di setiap penyelenggaraan tahapan. Peringkat yang disediakan adalah Utama, Madya, dan Pratama. Peringkat pratama didapatkan apabila pengukuran menggunakan rating tools mendapatkan poin $70 \%-75 \%$ dari total poin maksimal dimana mengindikasikan bangunan telah sesuai dengan Persyaratan Teknis Permen PU Nomor 29 Tahun 2006. Peringkat madya didapatkan apabila pengukuran menggunakan rating tools mendapatkan poin lebih dari $75-85 \%$ dari total poin maksimal dimana mengindikasikan bangunan telah sesuai dengan Parameter Permen Nomor 02/PRT/M/2015. Peringkat utama didapatkan apabila pengukuran menggunakan rating tools mendapatkan poin lebih dari $85-100 \%$ dari total poin maksimal, hal ini mengindikasikan bahwa bangunan berada diatas kinerja peraturan yang dipersyaratkan.

\section{Metode Penelitian}

Penelitian ini menggunakan metode kualitatif induktif. Dalam melakukan penilaian terhadap parameter bangunan hijau menggunakan tolok ukur yang jelas menurut Permen PUPR Nomor 2 Tahun 2015. Dalam pembahasannya menggunakan pendekatan metode deskriptif.

Tahapan penelitian sebagaimana digambarkan dalam diagram berikut.

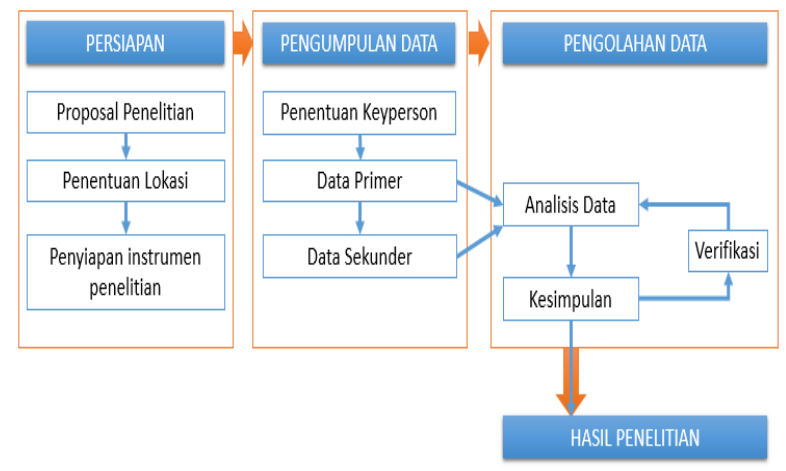

Gambar 1. Tahapan Penelitian (Author, 2019)

\section{Metode Pengumpulan Data}

Proses pengumpulan data diawali dengan menentukan keyperson yang dapat memberikan jalan bagi perolehan data-data secara lengkap, baik itu data sekunder dan data primer. Proses penentuan keyperson ini menggunakan beberapa kriteria, yaitu (1) narasumber adalah staf kunci yang mengetahui proses kegiatan retrofitting dari awal sampai akhir, (2) memiliki akses data retrofitting, dan (3) memiliki kemampuan menjelaskan dengan baik. Berdasarkan tiga kriteria tersebut, didapatkan satu orang staf koordinator kegiatan.

Pengumpulan data dilakukan dengan cara wawancara dengan keyperson untuk membuat daftar cek tentang data sekunder yang dapat digunakan. Data sekunder tersebut berupa (1) bahan laporan kegiatan, (2) tabel penilaian sebelum kegiatan retrofitting, dan tabel penilaian setelah dilakukan retrofitting. Kemudian data sekunder dikumpulkan untuk dianalisis.

\section{Metode Analisis}

Penelitian ini menggunakan metoda analisis deskriptif berdasarkan data sekunder berupa laporan kegiatan pengubahsuaian (retrofitting) serta data primer yang didapatkan dari hasil wawancara dengan keyperson. Analisis dilakukan dengan melihat hasil pencapaian kinerja persyaratan bangunan hijau setelah selesainya proses konstruksi pengubahsuaian dibandingkan dengan kondisi awal sebelum adanya pelaksanaan kegiatan pengubahsuaian.

Perbandingan dilakukan pada angka pencapaian kinerja sehingga didapatkan gambaran besaran gap antara poin maksimal yang dipersyaratkan dengan poin capaian pada kondisi awal bangunan sebelum dilakukan pengubahsuaian.

Adanya gap menggambarkan seberapa jauh pencapaian yang harus dikejar dan diwujudkan dalam kegiatan pengubahsuaian untuk memperkecil gap atau bahkan menghilangkan gap antara poin kinerja bangunan dengan poin maksimal yang dipersyaratkan. Analisis dilakukan terhadap usaha yang telah dilakukan untuk memperkecil gap tersebut, yaitu dengan melihat bentuk kegiatan penyesuaian hal-hal yang dipersyaratkan sesuai Permen PU No 2 Tahun 2015.

\section{Lokasi Penelitian}

Penelitian berlokasi di Bangunan Kantor Pusat Informasi Pengembangan Pemukiman dan Bangunan di Jalan Kenari Timoho Yogyakarta.

\section{Hasil}

Penilaian kinerja bangunan gedung hijau pada tahap perencanaan dilakukan terhadap pengelolaan tapak, efisiensi penggunaan energi, efisiensi penggunaan air, kualitas udara dalam ruang, material ramah lingkungan, pengelolaan sampah, dan pengelolaan air limbah.

\section{Pengelolaan Tapak}

Kondisi pengelolaan tapak bangunan digambarkan pada tabel berikut. 
Tabel 2. Kondisi Tapak Bangunan

\begin{tabular}{cccc}
\hline & \multicolumn{3}{c}{ Nilai } \\
PERSYARATAN & Poin & pada & Nilai pada \\
& Acuan & Kondisi & Retrofitting \\
& Awal & \\
\hline
\end{tabular}

A. Pengelolaan Tapak

\begin{tabular}{|c|c|c|c|c|}
\hline 1 & Orientasi Bangunan & 4 & 4 & 4 \\
\hline 2 & $\begin{array}{l}\text { Pengolahan Tapak } \\
\text { termasuk Aksesibilitas/ } \\
\text { Sirkulasi }\end{array}$ & 8 & 3 & 8 \\
\hline 3 & $\begin{array}{l}\text { Pengelolaan Lahan } \\
\text { Terkontaminasi Limbah } \\
\text { Bahan Berbahaya dan } \\
\text { Beracun (B3) }\end{array}$ & 3 & 3 & 3 \\
\hline 4 & $\begin{array}{l}\text { Rencana Ruang Terbuka } \\
\text { Hijau (RTH) Privat }\end{array}$ & 5 & 3 & 4 \\
\hline 5 & $\begin{array}{l}\text { Penyediaan Jalur Pejalan } \\
\text { Kaki (Pedestrian) }\end{array}$ & 7 & 3 & 7 \\
\hline 6 & $\begin{array}{l}\text { Pengelolaan Tapak } \\
\text { Besmen }\end{array}$ & 2 & 2 & 2 \\
\hline 7 & Penyediaan Lahan Parkir & 3 & 3 & 3 \\
\hline 8 & $\begin{array}{l}\text { Sistem Pencahayaan } \\
\text { Ruang Luar atau Halaman }\end{array}$ & 3 & 0 & 3 \\
\hline 9 & $\begin{array}{l}\text { Pembangunan Bangunan } \\
\text { Gedung di atas dan/atau } \\
\text { di Bawah Tanah, Air } \\
\text { dan/atau Prasarana/ Sarana } \\
\text { Umum }\end{array}$ & 6 & 6 & 6 \\
\hline \multicolumn{2}{|c|}{$\begin{array}{l}\text { Sub Total Penilaian } \\
\text { Pengelolaan Tapak }\end{array}$} & 41 & 27 & 40 \\
\hline
\end{tabular}

Sumber: diolah dari Data Perencanaan Retrofit Gedung PIP2B, 2018.

Bangunan sudah berada pada kondisi baik sesuai kriteria hijau sejak kondisi awal adalah pada persyaratan orientasi bangunan, pengolahan lahan terkontaminasi Limbah B3, pengelolaan tapak besmen, penyediaan lahan parkir dan pembangunan bangunan gedung di atas dan/ atau di Bawah Tanah, Air dan/atau Prasarana/ Sarana Umum. Hal ini berarti bahwa tidak diperlukan adanya kegiatan pengubahsuaian pada persyaratanpersyatan tersebut.

Kondisi yang sama sekali belum baik adalah pada sistem pencahayaan ruang luar atau halaman, artinya pada kondisi awal belum ada fasilitas penerangan yang dipasang menggunakan saklar otomatis atau sensor. Hal ini berarti perlu ada tindakan pengubahsuaian menuju persyaratan bangunan hijau.

Pada kondisi-kondisi yang belum baik maka dilakukan pengubahsuaian menuju kondisi bangunan hijau yang dipersyaratkan. Hal-hal yang diubahsuaikan adalah pada hal-hal berikut:

1. Pengolahan Tapak termasuk Aksesibilitas/Sirkulasi, dilakukan dengan penambahan vegetasi sehingga menambah jumlah tajuk vegetasi dibanding area tapak menjadi minimal 20\%, serta menambah vegetasi yang merupakan budidaya lokal skala provinsi menjadi minimal 60\% (Gambar 1).
2. Rencana Ruang Terbuka Hijau (RTH) Privat, dilakukan dengan penambahan area hijau.

3. Penyediaan Jalur Pejalan Kaki (Pedestrian), dilakukan dengan menambahkan jalur pedestrian dan fasilitas bagi pengguna sepeda (Gambar 2).

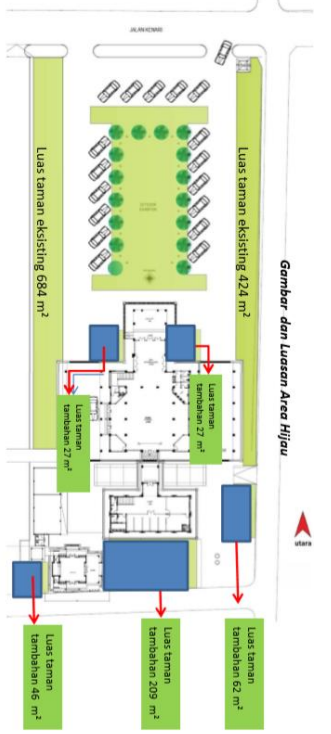

Gambar 1.

Ubahsuai RTH

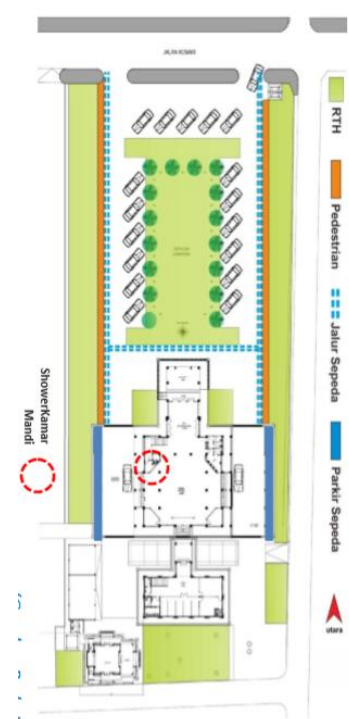

Gambar 2.

Jalur Pedestrian
Setelah dilakukan pengubahsuaian maka didapatkan poin rating tools yang mendekati maksimal. Nilai yang didapatkan pada pengelolaan tapak adalah 40 dari nilai maksimal 41.

\section{Efisiensi Penggunaan Energi}

Kondisi efisiensi penggunaan energi digambarkan pada tabel berikut.

Tabel 3. Kondisi Efisiensi Penggunaan Energi

\begin{tabular}{cccc}
\hline & \multicolumn{3}{c}{ Nilai } \\
PERSYARATAN & Poin & pada & Nilai pada \\
& Acuan & Kondisi & Retrofitting \\
& Awal \\
\hline
\end{tabular}

B. Efisiensi Penggunaan Energi

\begin{tabular}{|c|c|c|c|c|}
\hline 1 & Selubung Bangunan & 12 & 7 & 12 \\
\hline 2 & Sistem Ventilasi & 4 & 3 & 4 \\
\hline 3 & $\begin{array}{l}\text { Sistem Pengkondisian } \\
\text { Udara }\end{array}$ & 7 & 7 & 7 \\
\hline 4 & Sistem Pencahayaan & 12 & 4 & 10 \\
\hline 5 & $\begin{array}{l}\text { Sistem Transportasi dalam } \\
\text { gedung }\end{array}$ & 2 & 2 & 2 \\
\hline 6 & Sistem Kelistrikan & 3 & 1 & 3 \\
\hline \multicolumn{2}{|c|}{$\begin{array}{l}\text { Sub Total Penilaian Efisiensi } \\
\text { Penggunaan Energi }\end{array}$} & 40 & 24 & 38 \\
\hline
\end{tabular}

Sumber: diolah dari Data Perencanaan Retrofit Gedung PIP2B, 2018. 
Bangunan sudah berada pada kondisi baik sesuai kriteria hijau sejak kondisi awal yaitu pada sistem pengkondisian udara dan sistem transportasi dalam gedung. Hal ini berarti tidak diperlukan adanya kegiatan pengubahsuaian pada persyaratan-persyatan tersebut.

Pada kondisi-kondisi yang belum baik maka dilakukan pengubahsuaian menuju kondisi bangunan hijau yang dipersyaratkan. Hal-hal yang diubahsuaikan adalah pada hal-hal berikut:

1. Selubung bangunan, dilakukan dengan menyesuaikan nilai OTTV dan RTTV kurang dari 35 watt $/ \mathrm{m} 2$, serta dengan menambahkan shading (Gambar 3).

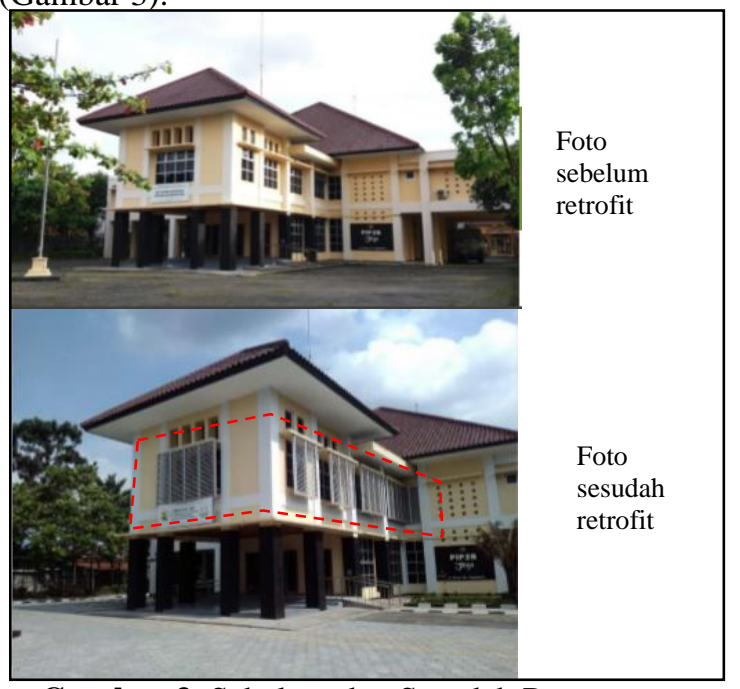

Gambar 3. Sebelum dan Sesudah Pemasangan Shading (dokumentasi PIP2B, 2018)

2. Sistem ventilasi, dilakukan dengan menyesuaikan sistem ventilasi alami sesuai dengan standar yang berlaku. Menurut Standar Nasional Indonesia standar untuk ventilasi alami adalah jumlah bukaan minimal $5 \%$ terhadap luas lantai ruangan yang membutuhkan ventilasi. Perhitungan yang dilakukan pada saat perencaan retrofitting menunjukkan bahwa ruangruang kantor memiliki prosentase bukaan jendela lebih dari $5 \%$.

3. Sistem pencahayaan, dilakukan dengan mengelompokkan lampu berdasarkan cahaya alami yang sampai ke ruang. Untuk ruang-ruang yang mendapatkan cahaya alami dipasang lampu dengan lux sensor, sedangkan untuk ruang yang tidak mendapatkan cahaya alami dipasang lampu dengan motion sensor (Gambar 3 dan 4).

4. Sistem kelistrikan, dilakukan dengan membuat sistem monitoring energi listrik secara terpadu berupa Building Management System (BMS) untuk memonitor pemakaian daya listrik dari waktu ke waktu.

Setelah dilakukan pengubahsuaian maka didapatkan poin rating tools mendekati maksimal. Nilai yang didapatkan pada efisiensi penggunaan energi adalah 38 dari nilai maksimal 40.

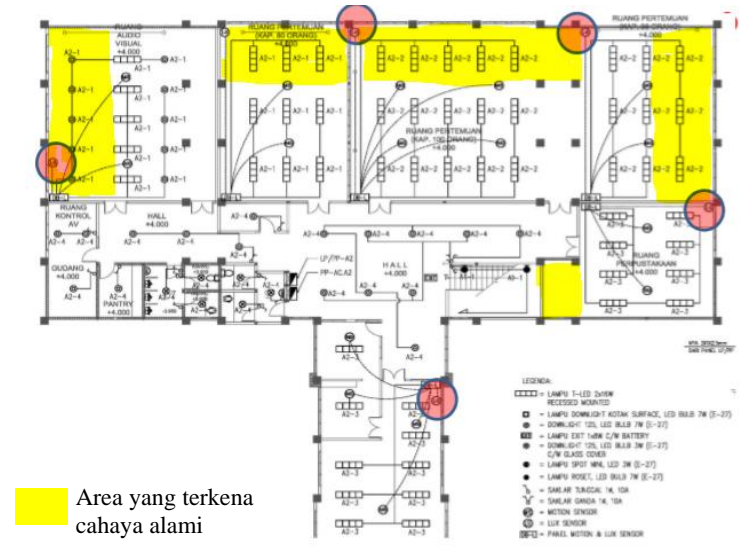

Gambar 4. Perletakan Lampu dengan Lux Sensor (PIP2B, 2018)

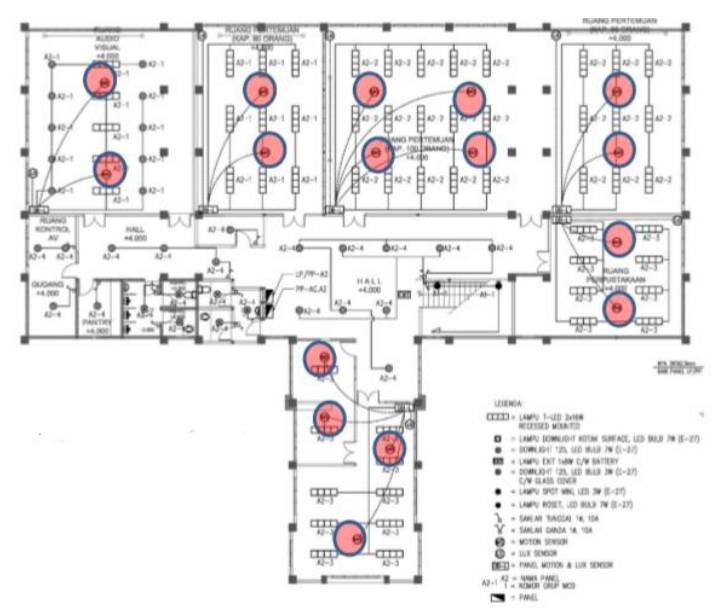

Gambar 5. Perletakan Lampu dengan Motion Sensor (PIP2B, 2018)

\section{Efisiensi Penggunaan Air}

. Kondisi efisiensi penggunaan air digambarkan pada tabel berikut.

Tabel 4. Kondisi Efisiensi Penggunaan Air

\begin{tabular}{lccc}
\hline \multicolumn{1}{c}{ PERSYARATAN } & $\begin{array}{c}\text { Poin } \\
\text { Acuan } \\
\text { Cilai } \\
\text { Kada } \\
\text { Awal }\end{array}$ & $\begin{array}{c}\text { Nilai pada } \\
\text { Retrofitting }\end{array}$ \\
\hline C. Efisiensi Penggunaan Air & & & \\
\hline $1 \quad$ Sumber Air & 12 & 0 & 4 \\
$2 \quad \begin{array}{l}\text { Pemakaian Air } \\
\quad \begin{array}{l}\text { Penggunaan Peralatan } \\
\text { Saniter Hemat Air (Water } \\
\text { Fixture) }\end{array}\end{array}$ & 5 & 0 & 5 \\
$\begin{array}{l}\text { Sub Total Penilaian Efisiensi } \\
\text { Penggunaan Air }\end{array}$ & $\mathbf{2 5}$ & $\mathbf{0}$ & $\mathbf{1 7}$ \\
\hline Sumber: diolah dari Data Perencanaan Retrofit Gedung PIP2B, 2018
\end{tabular}


Untuk persyaratan efisiensi penggunaan air, bangunan sama sekali belum berada pada kondisi baik sesuai kriteria hijau sejak kondisi awal.

Untuk itu semua hal yang menyangkut pemakaian air dalam bangunan diubahsuaikan, yaitu pada hal-hal berikut:

1. Sumber air, dilakukan dengan memasang sambungan PDAM dan memasang instalasi pengolahan air hujan.

2. Pemakaian air, dilakukan dengan memasang meteran air di setiap keluaran air PDAM, air tanah maupun air daur ulang.

3. Penggunaan peralatan saniter hemat air, dilakukan dengan mengganti peralatan saniter yang biasa dengan peralatan saniter hemat air, yaitu pada closet duduk dengan eco washer dan dual flush, urinal dengan sensor urinoir, shower dengan flow rate 9 liter per menit, serta keran wastafel/lavatory model tekan dengan flow rate 7 liter per menit.

Setelah dilakukan pengubahsuaian maka didapatkan poin rating tools naik mendekati maksimal. Nilai yang didapatkan pada efisiensi penggunaan air adalah 17 dari nilai maksimal 25.

\section{Kualitas Udara dalam Ruang}

Kondisi kualitas udara dalam ruang digambarkan pada tabel berikut.

Tabel 5. Kondisi Kualitas Udara Dalam Ruang

\begin{tabular}{cccc}
\hline & \multicolumn{3}{c}{ Nilai } \\
PERSYARATAN & Poin & pada & Nilai pada \\
& Acuan & Kondisi & Retrofitting \\
& & Awal & \\
\hline
\end{tabular}

D. Kualitas Udara Dalam

Ruang

\begin{tabular}{|c|c|c|c|c|}
\hline 1 & Pelarangan Merokok & 5 & 0 & 5 \\
\hline 2 & Pengendalian $\mathrm{CO}_{2}$ dan $\mathrm{CO}$ & 9 & 0 & 9 \\
\hline 3 & $\begin{array}{l}\text { Pengendalian penggunaan } \\
\text { bahan pembeku } \\
\text { (refrigerant) }\end{array}$ & 5 & 0 & 5 \\
\hline \multicolumn{2}{|c|}{$\begin{array}{l}\text { Sub Total Penilaian Kualitas } \\
\text { Udara dalam Ruang }\end{array}$} & 19 & 0 & 19 \\
\hline
\end{tabular}
PIP2B, 2018

Untuk persyaratan kualitas udara dalam ruang, bangunan sama sekali belum berada pada kondisi baik sesuai kriteria hijau sejak kondisi awal.

Untuk itu semua hal yang menyangkut kualitas udara dalam ruang diubahsuaikan, yaitu pada hal-hal berikut:

1. Pelarangan merokok, dilakukan dengan membuat komitmen pengelola gedung tentang pelarangan merokok, serta menambahkan rambu-rambu larangan merokok di tempat umum.

2. Pengendalian $\mathrm{CO} 2$ dan $\mathrm{CO}$, dilakukan dengan memasang alat utuk memonitor kadar $\mathrm{CO} 2$ dalam ruangan berupa detector dan alarm. Jika CO2 melebihi ambang batas, alarm akan berbunyi dan udara akan disedot menggunakan exhouse fan selanjutnya memasukkan udara segar dari luar ruangan (fresh air grill).

3. Pengendalian penggunaan bahan pembeku (refrigerant), dilakukan dengan menghindari penggunaan CFC pada refrigerant, serta memasang pendingi dengan nilai Global Warming Potential (GWP) rendah.

Setelah dilakukan pengubahsuaian maka didapatkan poin rating tools sama dengan nilai maksimal yang dipersyaratkan. Nilai yang didapatkan pada kualitas udara dalam ruang adalah 19 dari nilai maksimal 19.

\section{Material Ramah Lingkungan}

Kondisi material ramah lingkungan digambarkan pada tabel berikut.

Tabel 6. Kondisi Material Ramah Lingkungan

\begin{tabular}{cccc}
\hline & \multicolumn{3}{c}{ Nilai } \\
PERSYARATAN & Poin & pada & Nilai pada \\
& Acuan & Kondisi & Retrofitting \\
& & Awal & \\
\hline
\end{tabular}

E. Material Ramah Lingkungan

\begin{tabular}{llcc}
\hline $1 \quad \begin{array}{l}\text { Pengendalian Penggunaan } \\
\text { Material Berbahaya } \\
\text { Penggunaan Material }\end{array}$ & 7 & 7 & 1 \\
$2 \quad \begin{array}{l}\text { Bersertifikat Ramah } \\
\text { Lingkungan (Eco } \\
\text { Labelling) }\end{array}$ & 11 & 11 & 2 \\
$\begin{array}{l}\text { Sub Total Penilaian Material } \\
\text { Ramah Lingkungan }\end{array}$ & $\mathbf{1 8}$ & $\mathbf{1 8}$ & $\mathbf{1 8}$ \\
\hline
\end{tabular}

Sumber: diolah dari Data Perencanaan Retrofit Gedung PIP2B, 2018

Bangunan sudah berada pada kondisi baik sesuai kriteria hijau sejak kondisi awal yaitu pada penggunaan material ramah lingkungan. Hal ini berarti tidak diperlukan adanya kegiatan pengubahsuaian pada persyaratan-persyatan tersebut. Nilai yang didapatkan pada material ramah lingkungan adalah 18 dari nilai maksimal 18.

\section{Pengelolaan Sampah}

Untuk persyaratan pengelolaan sampah, bangunan sama sekali belum berada pada kondisi baik sesuai kriteria hijau sejak kondisi awal.

Untuk itu semua hal yang menyangkut pengelolaan sampah diubahsuaikan, yaitu pada hal-hal berikut:

1. Penerapan Prinsip 3R (reduce, reuse, recycle), dilakukan dengan cara Pengelola gedung berkomitmen untuk melakukan pembelian bahan atau barang yang tidak mengandung bahan berbahaya, tidak merusak lingkungan, tidak memerlukan distribusi panjang, tidak menimbulkan 
sampah. Hal ini dicantumkan dalam lampiran surat komitmen pengelola gedung.

2. Penerapan Sistem Penanganan Sampah, dilakukan dengan menempatkan fasilitas sampah, membangun fasilitas tempat pembuangan sementara di area gedung, mengusahakan pengurangan sampah dan penggunaan kembali sampah kantong plastik dan kertas, serta mengusahakan pemisahan sampah organik dan anorganik.

3. Penerapan Sistem Pencatatan Timbulan Sampah, dilakukan dengan membuat rencana pembukuan retribusi sampah per bulan dan melakukan pencatatan berat/volume timbulan sampah.

Setelah dilakukan pengubahsuaian maka didapatkan poin rating tools sama dengan nilai maksimal yang dipersyaratkan. Nilai yang didapatkan pada pengelolaan sampah adalah 10 dari nilai maksimal 10.

\section{Pengelolaan Air Limbah} tabel berikut.

Kondisi pengelolaan sampah digambarkan pada

Tabel 7. Kondisi Pengelolaan Sampah

\begin{tabular}{cccc}
\hline & \multicolumn{3}{c}{ Nilai } \\
PERSYARATAN & Poin & pada & Nilai pada \\
& Acuan & Kondisi & Retrofitting \\
& Awal & \\
\hline
\end{tabular}

F. Pengelolaan Sampah

\begin{tabular}{|c|c|c|c|c|}
\hline 1 & $\begin{array}{l}\text { Penerapan Prinsip 3R } \\
\text { (reduce, reuse, recycle) }\end{array}$ & 3 & 0 & 1 \\
\hline 2 & $\begin{array}{l}\text { Penerapan Sistem } \\
\text { Penanganan Sampah }\end{array}$ & 5 & 0 & 2 \\
\hline 3 & $\begin{array}{l}\text { Penerapan Sistem } \\
\text { Pencatatan Timbulan } \\
\text { Sampah }\end{array}$ & 2 & 0 & 3 \\
\hline \multicolumn{2}{|c|}{$\begin{array}{l}\text { Sub Total Penilaian } \\
\text { Pengelolaan Sampah }\end{array}$} & 10 & 0 & 10 \\
\hline
\end{tabular}

Sumber: diolah dari Data Perencanaan Retrofit Gedung PIP2B, 2018

Untuk persyaratan pengelolaan air limbah, bangunan sama sekali belum berada pada kondisi baik sesuai kriteria hijau sejak kondisi awal.

Untuk itu semua hal yang menyangkut pengelolaan air limbah diubahsuaikan, yaitu pada halhal berikut:

1. Penyediaan Fasilitas Pengelolaan Limbah Padat dan Limbah Cair Sebelum Dibuang ke Saluran Pembuangan Kota, dilakukan dengan memasang bio septictank portable (STP) dari semua keluaran pipa toilet,sehingga aoutput dari STP ini diharapkan memiliki kwalitas yang lebih ramah lingkungan.

2. Daur ulang air yang berasal dari limbah cair (grey water), namun hal ini belum dilakukan pengubahsuaian, sehingga nilai pada persyaratan ini masih nol.
Setelah dilakukan pengubahsuaian maka didapatkan poin rating tools naik mendekati nilai maksimal yang dipersyaratkan. Nilai yang didapatkan pada pengelolaan air limbah adalah 9 dari nilai maksimal 14.

\section{Pembahasan}

Kinerja bangunan hijau pada perencanaan retrofitting bangunan gedung PIP2B memiliki nilai maksimal pada pemenuhan sejumlah 3 (tiga) kriteria, yaitu kualitas udara dalam ruang, material ramah lingkungan dan pengelolaan sampah.

Kinerja yang nilainya masih nol adalah pada persyaratan daur ulang air yang berasal dari limbah cair (grey water). Dalam hal ini bangunan kantor PIP2B belum menggunakan kembali air hasil daur ulang dan belum melakukan pemeriksaan kualitas air daur ulang.

Kegiatan pengubahsuaian gedung PIP2B mampu menaikkan total skor dari $69(41,32 \%)$ pada konsisi awal menjadi $151 \quad(90,42 \%)$ pada kondisi setelah pengubahsuaian pada tujuh kriteria yang dipersyaratkan.

Nilai capaian persyaratan bangunan hijau pada kondisi awal dan pada kondisi setelah dilakukan pengubahsuaian dapat dilihat dalam tabel berikut.

Tabel 8. Total Nilai Kondisi Awal dan Setelah Pengubahsuaian (diolah dari Data Perencanaan Retrofit Gedung PIP2B, 2018.)

\begin{tabular}{|c|c|c|c|}
\hline PERSYARATAN & $\begin{array}{l}\text { Poin } \\
\text { Acuan }\end{array}$ & $\begin{array}{c}\text { Nilai pada } \\
\text { Kondisi } \\
\text { Awal }\end{array}$ & $\begin{array}{l}\text { Nilai pada } \\
\text { Retrofitting }\end{array}$ \\
\hline $\begin{array}{l}\text { Sub Total Penilaian } \\
\text { Pengelolaan Tapak }\end{array}$ & 41 & 27 & 40 \\
\hline $\begin{array}{l}\text { Sub Total Penilaian } \\
\text { Efisiensi Penggunaan } \\
\text { Energi }\end{array}$ & 40 & 24 & 38 \\
\hline $\begin{array}{l}\text { Sub Total Penilaian } \\
\text { Efisiensi Penggunaan Air } \\
\text { Sub Total Penilaian }\end{array}$ & 25 & 0 & 17 \\
\hline $\begin{array}{l}\text { Kualitas Udara dalam } \\
\text { Ruang }\end{array}$ & 19 & 0 & 19 \\
\hline $\begin{array}{l}\text { Sub Total Penilaian } \\
\text { Material Ramah } \\
\text { Lingkungan }\end{array}$ & 18 & 18 & 18 \\
\hline $\begin{array}{l}\text { Sub Total Penilaian } \\
\text { Pengelolaan Sampah }\end{array}$ & 10 & 0 & 10 \\
\hline $\begin{array}{l}\text { TOTAL POINT } \\
\text { TOTAL PROSENTASE }\end{array}$ & $\begin{array}{c}167 \\
100 \%\end{array}$ & $\begin{array}{c}69 \\
41,32 \%\end{array}$ & $\begin{array}{c}151 \\
90,42 \%\end{array}$ \\
\hline
\end{tabular}

\section{Kesimpulan}

Bangunan Kantor PIP2B pada kondisi awal (sebelum tahun 2018) bisa disebut sebagai bangunan pra hijau, dalam artian kinerja bangunan belum memenuhi syarat sebagai bangunan hijau. Hal ini berdasarkan pada nilai kinerja yang berada pada nilai $41,32 \%$.

Kondisi bangunan di tahun 2018 dilakukan pengubahsuaian (retrofitting) dengan menerapkan 
konsep bangunan hijau yang dipersyaratkan sesuai dengan Permen PU Nomor 2 Tahun 2015. Hasil dari pengubahsuaian kondisi kinerja bangunan PIP2B menunjukkan bahwa nilai kinerja naik menjadi $90,42 \%$. Angka ini menunjukkan bahwa dengan adanya pekerjaan pengubahsuaian dalam tahap perencanaan retrofitting maka kinerja bangunan PIP2B naik dari yang sebelumnya merupakan bangunan pra-hijau menjadi bangunan berpredikan bangunan hijau dengan peringkat utama.

\section{Daftar Pustaka}

Al-Kodmany, K. (2014) Green Retrofitting Skyscrapers: A Review, MDPI, Vol. 4, Issue 4, 10.3390/buildings4040683 retrieved from https://doi.org/10.3390/buildings4040683

Firnando, N, dkk., (2017) Penilaian Kriteria Green Building Pada Bangunan Gedung Rumah Sakit Universitas Sumatera Utara, Jurnal Teknik Sipil USU Vol. 6 No. 1 Tahun 2017, retrieved from https://jurnal.usu.ac.id/index.php/jts/article/view/ $\underline{16608}$

He, Qing, et al. (2019) Factors Influencing Residents' Intention toward Green Retrofitting of Existing Residential Buildings, Sustainability, Vol 11, Iss 15, p 4246 (2019) (2019-08-01T00:00:00Z) link: https://doi.org/10.3390/su11154246

Priatman, J. (2002) "Energy-Efficient Architecture" Paradigma Dan Manifestasi Arsitektur Hijau, 2002, Dimensi, Journal of Architecture and Built Environment, Vol 30, No. 2, retrieved from http://dimensi.petra.ac.id/index.php/ars/article/vie w/15778/15770

Peraturan Menteri Pekerjaan Umum dan Perumahan Rakyat Republik Indonesia Nomor 02/PRT/M/2015 Tentang Bangunan Gedung Hijau, http://jdih.pu.go.id/peraturandownload.html?id=228

Sudarwani, Maria, M. (2012) Penerapan Green Architecture Dan Green Building Sebagai Upaya Pencapaian Sustainable Architecture, Majalah Ilmiah Universitas Pandanaran Vol 10 No 24 Tahun 2012, retrieved from https://jurnal.unpand.ac.id/index.php/dinsain/artic le/view/90

Tasya, AF. \& Putranto, D. (2017) Konsep Green Building Pada Bangunan Kantor (Studi Kasus : Spasio Office,Surabaya), Jurnal Mahasiswa Jurusan Arsitektur Vol 5 No.4 Tahun 2017, retrieved from http://arsitektur.studentjournal.ub.ac.id/index.php /jma/article/view/418

Husin, SHC. (2017) Retrofitting Existing Building To Reduce Energy Consumption, Thesis/Undergraduate Project Paper, Universiti
Teknologi Malaysia, retrieved from https://bic.utm.my/files/2018/09/SITIMAHIRAH-CHE-HUSSIN-SBEC.pdf

Rahmawati A, Wisnumurti, Nugroho AM, (2018) Pengaruh Penerapan Green Retrofit Terhadap Life Cycle Cost Pada Bangunan Gedung, Vol 12, No 1, retrieved from https://rekayasasipil.ub.ac.id/index.php/rs/article/ view/489/397 